\title{
DESEMPENHO AGRONÔMICO DE CULTIVARES DE ALFACE SOB ADUBAÇÃO ORGÂNICA EM SEROPÉDICA - RJ
}

Rafael Guthier Tavares Goulart ${ }^{1}$, Carlos Antônio dos Santos ${ }^{2}$, Cristiana Maia de Oliveira², Evandro

Silva Pereira Costa ${ }^{3}$, Felipe Alves de Oliveira' ${ }^{1}$, Nairim Fidêncio de Andrade ${ }^{1}$, Margarida Goréte

Ferreira do $\mathrm{Carmo}^{4}$

\begin{abstract}
RESUMO - O objetivo do presente trabalho foi avaliar o efeito da aplicação de bokashi, esterco bovino e da combinação destes, sobre o crescimento e produtividade de nove cultivares de alface (Lactuca sativa L.) nas condições de Seropédica, RJ. O ensaio foi realizado em condições de campo no período de setembro a outubro de 2017. Utilizaram-se como tratamentos: quatro tipos de adubação - bokashi $\left(0,5 \mathrm{~kg} \mathrm{~m}^{-2}\right), \mathrm{mistura}^{-}$ de bokashi com esterco bovino $\left(0,250 \mathrm{~kg} \mathrm{~m}^{-2}+1,0 \mathrm{~kg} \mathrm{~m}^{-2}\right.$, respectivamente); esterco bovino $\left(1,0 \mathrm{~kg} \mathrm{~m}^{-2}\right)$ e testemunha - e nove cultivares de alface (Babá de Verão, Elisa, Mimosa, Grand Rapids, Camila, Sabrina, Grandes Lagos, Regina e Quatro Estações). O delineamento experimental adotado foi blocos ao acaso com quatro repetições em esquema fatorial 4x9. Avaliaram-se o diâmetro da cabeça $(\mathrm{cm})$, biomassa fresca da cabeça $\left(\mathrm{g} \mathrm{planta}^{-1}\right)$, número de folhas e produtividade estimada $\left(\mathrm{t} \mathrm{ha}^{-1}\right)$. Não houve efeito significativo da interação adubação x cultivar sobre as variáveis analisadas. As cultivares Grandes Lagos e Grand Rapids apresentaram maior produção de biomassa fresca da cabeça e produtividade que as demais. A alface respondeu positivamente a adubação orgânica. O composto bokashi, na dose utilizada, foi o que proporcionou melhores ganhos em crescimento e produtividade para a cultura. A utilização de esterco bovino também favoreceu o desempenho da cultura.
\end{abstract}

Palavras chave: adubo orgânico, bokashi, esterco bovino, Lactuca sativa L.

\section{AGRONOMIC PERFORMANCE OF LETTUCE CULTIVARS UNDER ORGANIC FERTILIZATION IN SEROPÉDICA, RJ}

\begin{abstract}
The present work aimed to evaluate the application effect of bokashi, bovine manure, as well as, the combination of them on the growth and yield of nine lettuce cultivars (Lactuta sativa L.) under the conditions of Seropedica-RJ weather. The work was performed under field conditions during the period from September to October in 2017. The treatments consisted of four combinations of fertilizing: bokashi (0.5 $\left.\mathrm{kg} \mathrm{m}^{-2}\right)$; mixture of bokashi and bovine manure $\left(0.250 \mathrm{~kg} \mathrm{~m}^{-2}+1.0 \mathrm{~kg} \mathrm{~m}^{-2}\right.$, respectively); bovine manure fertilization (2.0 kg m${ }^{-2}$ ) and control treatment, in combination with nine lettuce cultivars (Baba de Verão, Elisa, Mimosa, Grand Rapids, Camila, Sabrina, Grande Lagos, Regina, and Quatro Estações). The experimental design was randomized blocks with four replicates in a $4 \times 9$ factorial design, with different fertilizer sources and cultivars, respectively. Diameter $(\mathrm{cm})$, fresh biomass of the plant ( planta $\left.^{-1}\right)$, number of leaves and productivity $\left(\mathrm{t} \mathrm{ha} \mathrm{a}^{-1}\right)$, were assessed. No significant effect was observed for the fertilizing x cultivar interaction in all variables analyzed. Higher fresh biomass and productivity were observed in Grandes Lagos and Grand Rapids cultivars. The lettuce showed positive results to the organic fertilizing and bokashi, which provided better gain in growth and productivity. Bovine manure also showed interesting results in the crop performance representing another possibility to be used by farmer.
\end{abstract}

Keywords: bokashi, bovine manure, Lactuta sativa L., organic fertilizer.

\footnotetext{
${ }^{1}$ Discentes no curso de graduação em agronomia da Universidade Federal Rural do Rio de Janeiro (UFRRJ).

${ }^{2}$ Discente no curso de pós-graduação em Fitotecnia da UFRRJ.

${ }^{3}$ Engenheiro-agrônomo no Departamento de Fitotecnia da UFRRJ.

${ }^{4}$ Professora no Departamento de Fitotecnia da UFRRJ. Autora para correspondência: gorete@ufrrj.br
} 


\section{INTRODUÇÃO}

A alface (Lactuca sativa L.) destaca-se como a hortaliça folhosa mais consumida e a terceira em volume produzido no Brasil (ABCSEM, 2016). É uma cultura de ciclo rápido, comercializado o ano inteiro e, geralmente, cultivada em cinturões verdes, localizados próximos aos grandes centros consumidores. Seu cultivo próximo aos centros urbanos deve-se ao reduzido período de pós-colheita decorrente do alto teor de água e área foliar (Vidigal et al., 1995; Santos et al., 2001).

As cultivares de alface disponíveis no mercado brasileiro de sementes podem ser agrupadas em cinco grupos morfológicos principais, com base na formação de cabeça e tipo de folhas: repolhuda lisa, repolhuda crespa ou americana, solta lisa, solta crespa, solta crespa roxa e romana (Henz \& Suinaga, 2009). O sua produção e qualidade é favorecida por clima amenos e dias mais curtos. Dentro destes diferentes grupos, porém, existem cultivares adaptadas a diferentes condições climáticas o que permite o cultivo de alface em diferentes épocas do ano, dependendo da região (Filgueira, 2008). Para sucesso na produção de alface é necessário um adequado planejamento, que envolve a escolha das cultivares para as distintas épocas de plantio. Pouco se sabe sobre o comportamento de algumas cultivares de alface em regiões de baixada mais quente e úmida como é o caso de Seropédica, RJ. Este município localizase muito próximo ao grande mercado da Região Metropolitana do Rio de Janeiro e pode ampliar a sua produção, em área e épocas de colheita, mediante um estudo prévio de avaliação de cultivares e épocas de plantio. Ainda, existe a necessidade de se buscar novas formas de manejo que possam agregar melhorias a produção da cultura nessas regiões.

A adubação orgânica na cultura da alface pode substituir totalmente a adubação mineral. A quantidade a ser empregada depende da qualidade do adubo disponível e das condições locais - solo, clima e manejo (Freire et al., 2013). São obtidas maiores produções para a cultura a partir da melhoria das características químicas e físicas do solo, as quais podem ser alcançadas com o fornecimento de adubos orgânicos (Souza et al., 2005).

No geral, a oferta de matéria orgânica pode ser feita através de adubação orgânica com o uso de esterco bovino. Autores como Mantovani et al. (2017) estudaram a adubação com esterco bovino em hortaliças folhosas e concluíram que houve aumento na produção de alface, rúcula e almeirão, cultivados de forma sucessiva em função da utilização do esterco. Entretanto, sabe-se quem nem sempre existe a disponibilidade de esterco dependendo da região, o que motiva a busca por opções alternativas para produtor.

O bokashi, composto fermentado, é um adubo orgânico que apresenta como vantagem o uso de resíduos facilmente encontrados em várias regiões. Diversos tipos de ingredientes podem ser usados na sua formulação, como farelo de trigo e torta de mamona, que devem ser inoculados com microrganismos, seja em formulação comercial como o Embiotic ${ }^{\mathbb{R}}$, culturas microbianas como kefir ou microrganismos isolados a partir de iscas na mata. Estes funcionam como aceleradores da compostagem. Seu uso fornece, de forma mais lenta, a disponibilidade de nutrientes para a planta, sem que a mesma seja comprometida (Siqueira \& Siqueira, 2013).

Diversos estudos apontam a eficiência no uso da adubação orgânica. Fonseca (2013) avaliando a aplicação de bokashi constatou melhoria no desempenho agronômico nas culturas alface e rúcula. Sampaio et al. (2007) testaram a eficiência da adubação orgânica com esterco bovino na cultura do milho. Souza et al. (2016) abordam o uso de doses de bokashi na produção orgânica de alface crespa. Pouco se conhece, porém, sobre os efeitos da combinação entre bokashi e esterco bovino aplicados nas dosagens usualmente utilizadas pelos produtores, em diferentes cultivares de alface nas condições de Seropédica, RJ.

Diante do exposto, o objetivo desse trabalho foi avaliar o efeito da aplicação de bokashi, esterco bovino, e da combinação destes, sobre o crescimento e produtividade de nove cultivares de alface nas condições de Seropédica-RJ.

\section{MATERIALE MÉTODOS}

O experimento foi conduzido no Setor de Horticultura do Departamento de Fitotecnia da Universidade Federal Rural do Rio de Janeiro (UFRRJ), localizada no município de Seropédica-RJ, latitude $22^{\circ} 45^{\prime} \mathrm{S}$, longitude $43^{\circ} 41^{\prime} \mathrm{W}$ e altitude de $33 \mathrm{~m}$, sendo o clima do tipo Aw na classificação de Köppen (1948). O ensaio foi realizado de setembro a outubro de 2017.

Utilizaram-se como tratamentos quatro tipos de adubação orgânica: T1 - bokashi $\left(0,5 \mathrm{~kg} \mathrm{~m}^{-2}\right)$; $\mathrm{T} 2$ - mistura de bokashi + esterco bovino $\left(0,3 \mathrm{~kg} \mathrm{~m}^{-2}+1,2 \mathrm{~kg} \mathrm{~m}^{-2}\right.$, 
respectivamente); T3- adubação com esterco bovino $\left(2,0 \mathrm{~kg} \mathrm{~m}^{-2}\right)$ e T4 - testemunha (sem adubação), em combinação à nove cultivares de alface (Babá de Verão, Elisa, Mimosa, Grand Rapids, Camila, Sabrina, Grandes Lagos, Regina, e Quatro Estações). O delineamento experimental adotado foi blocos ao acaso com quatro repetições em esquema fatorial $4 \times 9$, sendo as diferentes fontes de adubação e cultivares, respectivamente.

A escolha das quantidades de adubos e das cultivares de alface utilizadas foram feitas com base no Manual de Calagem e Adubação do Estado do Rio de Janeiro (Freire et al., 2013) e na tradição de uso e dosagens feitas pelos produtores de alface da região de Seropédica-RJ.

O composto fermentado do tipo bokashi foi elaborado de acordo com o manual técnico do Programa Rio Rural (Siqueira \& Siqueira, 2013) utilizando-se 600 $\mathrm{kg}$ de farelo de trigo, $400 \mathrm{~kg}$ de torta de mamona, 2 litros da solução de microrganismos capturados em mata (com uso de arroz cozido) e previamente ativados em melaço, além da adição de água, dependendo da necessidade. Após 21 dias de fermentação anaeróbica obteve-se o composto, bokashi, com as seguintes características: $51,90 \%$ de C; 4,2\% de N; Relação C:N de 12,$3 ; 8,7 \mathrm{~g} \mathrm{~kg}^{-1} \mathrm{de} \mathrm{P} ; 11,9 \mathrm{~g} \mathrm{~kg}^{-1}$ de $\mathrm{K} ; 9,6 \mathrm{~g} \mathrm{~kg}^{-1} \mathrm{de}$ $\mathrm{Ca} ; \mathrm{e} 6,6 \mathrm{~g} \mathrm{~kg}^{-1} \mathrm{de} \mathrm{Mg}$.

As mudas de alface foram produzidas em bandejas de 200 células, preenchidas com substrato comercial para hortaliças (Multiplant ${ }^{\mathbb{}}$ ) em casa de vegetação fechada. O transplantio para canteiros a campo foi realizado 30 dias após a semeadura.

O solo da área experimental foi classificado como Planossolo háplico e apresentava as seguintes características físicas e químicas na profundidade de $0-20 \mathrm{~cm}$ : textura expedita (arenosa); $\mathrm{pH}$ (água) $=4,60$; $\mathrm{Al}=0,20 \mathrm{cmol}_{\mathrm{c}} \mathrm{dm}^{-3} ; \mathrm{H}+\mathrm{Al}($ Acidez potencial $)=3,50$ $\mathrm{cmol}_{\mathrm{c}} \mathrm{dm}^{-3} ; \mathrm{Ca}=1,20 \mathrm{cmol}_{\mathrm{c}} \mathrm{dm}^{-3} ; \mathrm{Mg}=0,50 \mathrm{cmol}_{\mathrm{c}} \mathrm{dm}^{-3}$; $\mathrm{SB}$ (Soma de bases) $=1,90 \mathrm{cmol}_{\mathrm{c}} \mathrm{dm}^{-3} ; \mathrm{T}$ (Capacidade de Troca Catiônica) $=5,40 \mathrm{cmol}_{\mathrm{c}} \mathrm{dm}^{-3} ; \mathrm{V}$ (Saturação por bases $)=35,0 \% ; \mathrm{m}$ (Saturação por alumínio $)=9,0 \%$, $\mathrm{P}=36,0 \mathrm{mg} \mathrm{dm}^{-3} ; \mathrm{K}=51,0 \mathrm{mg} \mathrm{dm}^{-3}$. Na profundidade de 20-40 cm, as características encontradas foram: textura arenosa; $\mathrm{pH}$ (água) $=4,50 ; \mathrm{Al}=0,30 \mathrm{cmol}_{\mathrm{c}} \mathrm{dm}^{-3} ; \mathrm{H}+$ $\mathrm{Al}=3,50 \mathrm{cmol}_{\mathrm{c}} \mathrm{dm}^{-3} ; \mathrm{Ca}=0,90 \mathrm{cmol}_{\mathrm{c}} \mathrm{dm}^{-3} ; \mathrm{Mg}=0,40$ $\mathrm{cmol}_{\mathrm{c}} \mathrm{dm}^{-3} ; \mathrm{SB}=1,50 \mathrm{cmol}_{\mathrm{c}} \mathrm{dm}^{-3} ; \mathrm{T}=5,0 \mathrm{cmol}_{\mathrm{c}} \mathrm{dm}^{-3}$; $\mathrm{V}=30,0 \% ; \mathrm{m}=17,0 \%, \mathrm{P}=40,0 \mathrm{mg} \mathrm{dm}^{-3} ; \mathrm{K}=53,0$ $\mathrm{mg} \mathrm{dm}{ }^{-3}$.
Os canteiros apresentaram dimensões de $1,0 \mathrm{~m}$ de largura e 36,0 m de comprimento sendo 1,0 $\mathrm{m}$ de comprimento por parcela. Utilizou-se o espaçamento de $25 \times 25 \mathrm{~cm}$ entre plantas, totalizando-se 16 plantas por parcela. Para fins de colheita e avaliação, consideraram-se as quatro plantas centrais.

Os adubos orgânicos foram aplicados no dia anterior ao plantio (40\%) por meio de incorporação ao solo com uso de enxada e os $60 \%$ restantes foram aplicados em cobertura aos 21 dias após o transplantio (DAT).

A irrigação foi realizada por aspersão, de duas a três vezes ao dia, a depender das condições climáticas e necessidade das plantas. O controle das plantas espontâneas foi feito por meio de capinas manuais, realizadas aos 15 e 20 DAT. Não houve necessidade de controle fitossanitário.

As colheitas foram realizadas aos 40, 41, 42 e 43 DAT onde foram avaliadas as seguintes variáveis fitotécnicas: diâmetro da cabeça $(\mathrm{cm})$, biomassa fresca da cabeça $\left(\mathrm{g} \mathrm{planta}^{-1}\right)$, e número de folhas. Inicialmente, a parte aérea de cada planta foi separada de suas raízes por meio do corte na base da cabeça. Em seguida, realizouse a limpeza e remoção das folhas sem padrão comercial e com aparência sujas ou em processo de senescência, doentes e danificadas. As folhas foram contadas e o diâmetro das cabeças foi determinado com auxílio de uma régua acoplada a um suporte de madeira, similar a um paquímetro, enquanto que a biomassa fresca comercial foi obtida por meio de pesagem em balança analítica. Adicionalmente, foi estimada a produtividade $\left(\mathrm{t} \mathrm{ha}^{-1}\right)$ com base nos valores de biomassa fresca da cabeça e espaçamento adotado, e considerando-se, ainda, a área útil do hectare cultivado, isto é, desprezandose as áreas de $40 \mathrm{~cm}$ entre os canteiros.

Os dados obtidos foram submetidos à análise de variância (ANOVA) e as médias foram agrupadas pelo teste de Scott-Knott a 5\% de probabilidade utilizandose o software estatístico SISVAR (Ferreira, 2011). Os dados foram transformados por " $\mathrm{x}$.

\section{RESULTADOS E DISCUSSÃO}

Foram observados efeitos significativos (Pd"0,05) de cultivar sobre todas as variáveis avaliadas, com exceção ao diâmetro das cabeças. De igual forma, todas as variáveis foram influenciadas pelos tipos de adubo orgânico (Tabela 1), não havendo interação 
estatisticamente significativa $(\mathrm{P} \leq 0,05)$ entre as cultivares e adubos utilizados (Tabela 1).

Os diâmetros das cabeças (DC) obtidos nesse ensaio se situaram entre 17,75 a 22,96 cm, sem diferenças significativas quanto a cultivar. Para a variável biomassa fresca da cabeça (BFC), a cultivar Grandes Lagos obteve melhor média, com 290 g planta $^{-1}$, diferindo estatisticamente das demais. Em seguida, destacou-se a cultivar Grand Rapids, com 210 g $_{\text {planta }}{ }^{-1}$. Um terceiro grupo foi formado com as demais cultivares, que exibiram valores de BFC na faixa de 120 a $180 \mathrm{~g} \mathrm{planta}^{-1}$ (Tabela 2).

Em relação ao número de folhas (NF), as maiores médias foram obtidas pelas cultivares Baba de Verão (36,57 folhas), Elisa (34,07 folhas) e Regina (39,39 folhas) (Tabela 2), as quais não apresentaram diferenças estatísticas entre si e foram superiores às demais. Um segundo grupo foi formado pelas cultivares Grandes Lagos, Grand Rapids, Mimosa e Quatro Estações, que apresentaram valores médios variando de 25,06 a 29,95 folhas por planta. O menor número de folhas foi observado nas cultivares Camila (21,65 unidades) e Sabrina (19,60 unidades).

Em função do maior valor de biomassa fresca de cabeça (BFC) produzida pela cultivar Grandes Lagos, classificou-se esta como a de maior produtividade estimada (33,52 $\left.\mathrm{t} \mathrm{ha}^{-1}\right)$, seguido por Grand Rapids $\left(25,13 \mathrm{t} \mathrm{ha}^{-1}\right)$ e pelas demais cultivares que apresentaram produtividade estimada variando entre 15,83 a $21,22 \mathrm{t} \mathrm{ha}^{-1}$ (Tabela 2).

Estes resultados são compatíveis e superiores aos relatados por Fiorini et al. (2016) em estudo realizado neste mesmo município no período de primavera. Estes autores relataram para a cultivar Grand Rapids valores de BFC igual a 176,59 $\mathrm{g} \mathrm{planta}^{-1}$, enquanto que para a cultivar Elisa, os valores foram de 140,74 $\mathrm{g} \mathrm{planta}^{-1}$. Vale ressaltar que, neste presente estudo não houve diferenças acentuadas entre as cultivares avaliadas quanto à biomassa fresca de cabeça e à produtividade

Tabela 1 - Análise de variância das variáveis fitotécnicas: diâmetro de cabeça (DC), biomassa fresca de cabeça (DBC), número de folhas (NF) e produtividade estimada, em função do uso de cultivares de alface (Lactuca sativa L.) e tipos de adubo orgânico. Seropédica, UFRRJ, 2017

\begin{tabular}{lccccc}
\hline \multirow{2}{*}{ Fontes de variação } & GL & \multicolumn{3}{c}{ Quadrado médio (QM) } \\
\cline { 3 - 6 } & & DC & BFC & NF & Produtividade \\
\hline Cultivar (A) & 7 & $0,619^{\text {ns }}$ & $0,056^{*}$ & $7,150^{*}$ & $9,021^{*}$ \\
Adubo orgânico (A) & 3 & $7,354^{*}$ & $0,328^{*}$ & $15,357^{*}$ & $72,719^{*}$ \\
Interação (C) x (A) & 21 & $0,164^{\text {ns }}$ & $0,003^{\text {ns }}$ & $0,491^{\text {ns }}$ & $0,665^{\text {ns }}$ \\
Bloco & 3 & $6,908^{*}$ & $0,101^{*}$ & $5,581^{\text {ns }}$ & $19,843^{*}$ \\
Resíduo & 109 & 0,422 & 0,01 & 0,714 & 2,349 \\
CV(\%) & & 14,74 & 30,26 & 15,84 & 31,15 \\
\hline
\end{tabular}

*Significativo $(\mathrm{p} \leq 0,05)$; ${ }^{\mathrm{NS}}$ não significativo.

Tabela 2 - Médias das variáveis fitotécnicas: diâmetro de cabeça (DC), biomassa fresca da cabeça (BFC), número de folhas (NF) e produtividade estimada de diferentes cultivares de alface. Seropédica, UFRRJ, 2017

\begin{tabular}{|c|c|c|c|c|}
\hline Cultivares & $\mathrm{DC}(\mathrm{cm})$ & $\mathrm{BFC}\left(\mathrm{g}_{\mathrm{planta}}{ }^{-1}\right)$ & NF & Produtividade $\left(\mathrm{t} \mathrm{ha}^{-1}\right)$ \\
\hline Baba de verão & $18,71 \mathrm{a}$ & $160,0 \mathrm{c}$ & $36,57 \mathrm{a}$ & $19,19 \mathrm{c}$ \\
\hline Camila & $21,86 \mathrm{a}$ & $140,0 \mathrm{c}$ & $21,65 \mathrm{c}$ & $17,12 \mathrm{c}$ \\
\hline Elisa & $20,11 \mathrm{a}$ & $150,0 \mathrm{c}$ & $34,07 \mathrm{a}$ & $17,28 \mathrm{c}$ \\
\hline Grandes Lagos & 22,96 a & 290,0 a & $27,31 \mathrm{~b}$ & 33,52 a \\
\hline Grand Rapids & $21,01 \mathrm{a}$ & $210,0 \mathrm{~b}$ & $25,46 \mathrm{~b}$ & $25,13 \mathrm{~b}$ \\
\hline Mimosa & $19,81 \mathrm{a}$ & $150,0 \mathrm{c}$ & $25,06 \mathrm{~b}$ & $17,47 \mathrm{c}$ \\
\hline Quatro Estações & $17,75 \mathrm{a}$ & $120,0 \mathrm{c}$ & $29,95 \mathrm{~b}$ & $13,98 \mathrm{c}$ \\
\hline Regina & $19,27 \mathrm{a}$ & $180,0 \mathrm{c}$ & 39,39 a & $21,22 \mathrm{c}$ \\
\hline Sabrina & 20,19 a & $130,0 \mathrm{c}$ & $19,60 \mathrm{c}$ & $15,83 \mathrm{c}$ \\
\hline CV $(\%)$ & 14,74 & 30,16 & 15,84 & 31,15 \\
\hline
\end{tabular}

* Médias seguidas pela mesma letra não diferem entre si pelo teste de Scott-Knott a $5 \%$ de probabilidade. 
estimada, com exceção das cultivares Grandes Lagos e Grand Rapids.

Os diâmetros de cabeça (DC) foram influenciados pelos tipos de adubação. Os maiores DC foram observados nos tratamentos com esterco bovino $(22,72$ $\mathrm{cm})$ e bokashi $(22,44 \mathrm{~cm})$, aplicados isoladamente, seguido do tratamento com a combinação dos dois adubos $(19,99$ $\mathrm{cm})$. Estes tratamentos foram estatisticamente superiores à testemunha (sem adubação) que apresentou valor médio de DC igual a 15,23 cm (Tabela 3).

Maior biomassa fresca da cabeça (BFC) foi observada nas plantas adubadas com bokashi $(250,0$ g planta $\left.{ }^{-1}\right)$, seguido das plantas adubadas com esterco bovino $\left(200,0 \mathrm{~g} \mathrm{planta}^{-1}\right)$ e mistura bokashi + esterco bovino $\left(170,0 \mathrm{~kg} \mathrm{planta}^{-1}\right)$ que não diferiram entre si. Todos os três tratamentos foram significativamente superiores à testemunha $\left(70,0\right.$ g planta $\left.^{-1}\right)$ (Tabela 3$)$. Consequentemente, a maior produtividade estimada, $28,87 \mathrm{tha}^{-1}$, foi observada no tratamento com bokashi, seguido dos tratamentos com esterco bovino $(23,34$ $\mathrm{t} \mathrm{ha}^{-1}$ ) e pela combinação de bokashi + esterco bovino $\left(20,51 \mathrm{t} \mathrm{ha}^{-1}\right)$. A menor produtividade foi registrada no tratamento testemunha $\left(8,07 \mathrm{tha}^{-1}\right)$ (Tabela 3$)$.

Os três tipos de adubação resultaram em maior número de folhas (NF), de 30,20 a 34,65, comparados à testemunha, com 21,07 folhas (Tabela 3 ).

Resultados positivos com a utilização de esterco bovino também foram observados por Santos et al. (2015) para a variável matéria fresca da parte aérea de alface. Estes autores relatam valores de 276,03 g planta $^{-1}$ com a aplicação de $74,72 \mathrm{tha}^{-1}$ de esterco bovino, e 221,90 g planta $^{-1}$ para a testemunha. Ou seja, observaram incrementos de $19,61 \%$ na produção de matéria fresca da parte aérea de alface em relação ao tratamento que não foi adubado (testemunha).

Nas condições do presente estudo, as respostas da adubação orgânica quanto à produção de biomassa fresca de cabeça foram mais pronunciadas, observandose incrementos de $250,0 \%$, em relação à testemunha (sem adubação) com aplicação de $0,5 \mathrm{~kg}$ de bokashi por $\mathrm{m}^{2} ; 200,0 \%$ com aplicação de $2,0 \mathrm{~kg}$ de esterco bovino por $\mathrm{m}^{2}$; e $170,0 \%$ com a aplicação de $0,3 \mathrm{~kg}$ de bokashi $+1,200 \mathrm{~kg}$ de esterco bovino por $\mathrm{m}^{2}$. As diferenças tão marcantes com relação à testemunha podem ser decorrentes das condições físicas químicas do solo utilizado, sendo textura arenosa, baixo $\mathrm{pH}$ e teores de nutrientes. A adubação com bokashi apresentou os melhores resultados para todas as variáveis analisadas, em especial o acúmulo de biomasssa fresca e, consequentemente, de produtividade. Ou seja, dentre os tipos de adubação avaliados e considerando-se as doses aplicadas, foi o que mais favoreceu o desenvolvimento das plantas de alface, independente da cultivar. Uma possível explicação para o bom desempenho desse adubo é o fato deste disponibilizar mais lentamente os nutrientes para as plantas (Siqueira \& Siqueira, 2013) o que reduz as perdas. Ainda, o uso de bokashi tem sido recomendado na recuperação de solos degradados e na transição agroecológica por contribuir para o reestabelecimento do equilíbrio dos organismos presentes no solo e quebra do ciclo de doenças e pragas (Homma, 2003; Siqueira \& Siqueira, 2013; Souza, 2015).

Souza et al. (2016), verificaram que tratamentos com doses crescentes de bokashi resultaram em respostas positivas quanto à massa fresca, número de folhas e diâmetro do caule, para a cultura da alface, quando comparados com a testemunha sem aplicação de nenhum tipo de fertilizante. Motta et al. (2010) avaliaram a

Tabela 3 - Médias das variáveis fitotécnicas: diâmetro (DC), biomassa fresca da cabeça (BFC), número de folhas (NF) e produtividade estimada de plantas de alface submetidas a diferentes tipos de adubação orgânica. Seropédica, UFRRJ, 2017

\begin{tabular}{|c|c|c|c|c|}
\hline Tipos de adubação ${ }^{1}$ & $\mathrm{DC}(\mathrm{cm})$ & $\mathrm{BFC}\left(\mathrm{g} \mathrm{planta}^{-1}\right)$ & NF & Produtividade $\left(\mathrm{t} \mathrm{ha}^{-1}\right)$ \\
\hline $\mathrm{T} 1$ & $22,44 \mathrm{a}$ & $250,0 \mathrm{a}$ & $33,47 \mathrm{a}$ & $28,87 \mathrm{a}$ \\
\hline $\mathrm{T} 2$ & $19,99 \mathrm{~b}$ & $170,0 \mathrm{~b}$ & $30,20 \mathrm{a}$ & $20,51 \mathrm{~b}$ \\
\hline T 3 & $22,72 \mathrm{a}$ & $200,0 \mathrm{~b}$ & 34,65 a & $23,34 \mathrm{~b}$ \\
\hline T 4 & $15,23 \mathrm{c}$ & $70,0 \mathrm{c}$ & $21,07 \mathrm{~b}$ & $8,07 \mathrm{c}$ \\
\hline $\mathrm{CV}(\%)$ & 14,74 & 30,16 & 15,84 & 31,15 \\
\hline
\end{tabular}

${ }^{1}$ Tipos de adubação: T1 - bokashi $\left(0,5 \mathrm{~kg} \mathrm{~m}^{-2}\right)$; T2 - mistura de bokashi + esterco bovino $\left(0,3 \mathrm{~kg} \mathrm{~m}^{-2}+1,2 \mathrm{~kg} \mathrm{~m}^{-2}\right.$, respectivamente); T3- adubação com esterco bovino $\left(2,0 \mathrm{~kg} \mathrm{~m}^{-2}\right)$ e T4 - testemunha (sem adubação). * Médias seguidas pela mesma letra na coluna não diferem entre si pelo teste de Scott-Knott a $5 \%$ de probabilidade. 
influência de diferentes concentrações de bokashi no substrato no desenvolvimento de mudas de alface cv. Lucy Brown, produzidas em bandejas e observaram aumento linear da massa fresca e seca das mudas de alface. Souza et al. (2008) utilizaram bokashi na cultura da alface e obtiveram um ganho significativo no número de folhas, quando comparado com as adubações minerais e co-produtos do biodiesel. Resultados positivos com uso de compostos orgânicos na cultura da alface também são reportados por Oliveira et al. (2009) e corroboram aos obtidos no presente estudo.

No que diz respeito às vantagens da adubação orgânica, Santiago e Rosseto (2015) relatam que esta favorece a maior disponibilidade de nutrientes às plantas; a redução do processo erosivo; a estimulação da atividade biológica; a maior agregação de partículas do solo; a maior retenção de água; a menor diferença de temperatura do solo durante o dia e a noite e ao aumento da taxa de infiltração. Entretanto a adubação orgânica também traz algumas limitações, como as citadas por Trani et al. (2013), ao qual relatam que alguns adubos orgânicos quando mal decompostos ou quando não possuem origem controlada, podem introduzir ou até favorecer alguns fitopatógenos habituais do solo como Verticillium, Fusarium e Rhizoctonia, e introduzir sementes de plantas espontâneas. Outro ponto a ser considerado é a relação carbono-nitrogênio (relação C:N) favorável. Se a relação $\mathrm{C}: \mathrm{N}$ for maior que 30:1, haverá a redução do crescimento de micro-organismos por falta de nitrogênio, ocasionando lentidão na decomposição do material; entretanto, se for menor, o excesso de nitrogênio pode acelerar a decomposição (Souza \& Rezende, 2003), o que pode, inclusive, ocasionar picos de indisponibilidade de $\mathrm{N}$ às plantas.

Deve-se considerar que, apesar do destaque com a aplicação de bokashi, os dois demais tratamentos, nas dosagens avaliadas, também favoreceram o desempenho de todas as cultivares de alface. Tendo em vista as respostas das plantas a estes três adubos, a escolha pelos produtores pode ser feita em função da disponibilidade destes insumos na região e dos seus respectivos custos.

\section{CONCLUSÕES}

A alface respondeu positivamente à adubação orgânica utilizada.
A fonte de adubação mais eficaz foi o bokashi, que resultou em maior crescimento e produtividade das plantas.

Nas condições e época de realização do ensaio, as cultivares Grandes Lagos e Grand Rapids foram as que apresentaram melhor desempenho agronômico e produtividade.

A escolha do adubo orgânico a ser utilizado pelo produtor deve considerar a disponibilidade dos insumos na região e os seus respectivos custos.

\section{AGRADECIMENTOS}

Coordenadoria de Produção Vegetal Integrada ao Ensino, Pesquisa, Extensão da Universidade Federal Rural do Rio de Janeiro (UFRRJ) e Departamento de Fitotecnia da UFRRJ.

\section{REFERÊNCIAS BIBLIOGRÁFICAS}

FERREIRA, D.F. Sisvar: a computer statistical analysis system. Ciência e Agrotecnologia, v.35, p.1039-1042, 2011. http://dx.doi.org/10.1590/ S1413-70542011000600001

FILGUEIRA, F.A.R. Novo manual de olericultura: agrotecnologia moderna na produção e comercialização de hortaliças. Viçosa: UFV, 2008. 421p.

FIORINI, C.V.A.; FERNANDES, M.C.A.; DUARTE, F.E.V.O. et al. Cultivares de alface sob manejo orgânico no inverno e na primavera na Baixada Fluminense. Agrária, v. 11, p.335-342, 2016. http://dx.doi.org/10.5039/agraria.v11i4a5405

FREIRE, L.R.; BALIEIRO, F. C.; ZONTA, E. et al. Manual de calagem e adubação do Rio de Janeiro. Seropédica: Editora Universidade Rural, 2013.430p.

FONSECA, J.O.G. Desempenho agronômico de alface e rúcula em função de doses de composto fermentado em condições de cultivo protegido, sob manejo orgânico em Nova Friburgo, RJ. Dissertação (Mestrado em Agricultura Orgânica). Seropédica, RJ: UFRR, 2013.61p.

HENZ G.P.; SUINAGA F. Tipos de alface cultivadas no Brasil. Brasília: Embrapa Hortaliças, 2009. 7p. (Comunicado Técnico, 75). 
HOMMA, S.K. Nutri-bokashi em respeito à natureza. São Paulo: Fundação Mokiti Okada, 2003. 47 p.

MANTOVANI, J.R.; CARRERA, M.; MOREIRA, J.L.A. et al. Fertility properties and leafy vegetable production in soil fertilized with cattle manure. Revista Caatinga, v.30, p.825-836, 2017. http://dx.doi.org/10.1590/1983-

21252017v30n402rc

MOTTA, I.S.; KOBAYASHI, L.A.; PADOVAN, M.P. et al. Produção de mudas de alface com diferentes concentrações de bokashi. Cadernos de Agroecologia, v.5, p.1-5, 2010.

OLIVEIRA, E.M.; QUEIROZ, S.B.; SILVA, V.F. Influência da matéria orgânica sobre a cultura da alface. Revista Engenharia Ambiental: pesquisa e tecnologia, v.6, p.285-292, 2009.

SAMPAIO, E.V.S.B.; OLIVEIRA, N.M.B.; NASCIMENTO, P.R.F. Eficiência da adubação orgânica com esterco bovino e com (Egeria densa). Revista Brasileira de Ciência do Solo, v.31, p.995-1002, 2007. http://dx.doi.org/ 10.1590/S0100-06832007000500016

SAntiago, A.D.; ROSSETTO, R. Adubação Orgânica. 2015. Disponível em: <http:// www.agencia.cnptia.embrapa.br/gestor/ canadeacucar/arvore/ ContaG01 37 71120051617.html>. (Acessado em 10 de novembro de 2017).

SANTOS, J. F.; XAVIER, J. F.; MENINO, I. B. et al. Produção de alface em função de adubação de esterco bovino em sistema agroecológico. In: I Congresso Internacional da Diversidade do Semiárido, 2015. Anais...Campina Grande, 2015.

SANTOS, R. H. S.; SILVA, F.; CASALI, V. W. D. et al. Conservação pós-colheita de alface cultivada com composto orgânico. Pesquisa

Agropecuária Brasileira, v.36, p.521-525, 2001. http://dx.doi.org/10.1590/S0100-

204X2001000300017
SIQUEIRA, A.P.P.; SIQUEIRA, M.F.B. Bokashi: adubo orgânico fermentado. Niterói: Programa Rio rural, 2013. 16p. (Manual Técnico 40).

SOUZA, L.H.; CAMPINA, V.; ALMEIDA, D. et al. Doses de bokashi na produção orgânica de alface crespa. Congresso Técnico Científico da Engenharia e da Agronomia CONTECC'2016 Rafain Palace Hotel \& Convention Center- Foz do Iguaçu, PR. 2016.

SOUZA, J.L. Agricultura orgânica: tecnologias para produção de alimentos saudáveis. 3ed. Vitória: INCAPER, 2015.

SOUZA, I.P. Adubação orgânica de alface com coprodutos do biodiesel. Dissertação (Mestrado em Agronomia). Lavras, MG: UFLA, 2008. 42p.

SOUZA J.L.; RESENDE, P. Manual de horticultura orgânica. 2a ed. Viçosa: Aprenda Fácil, 2003. 843p.

SOUZA, P.A.; NEGREIROS, M.Z.; MENEZES, J.B. et al. Características químicas de alface cultivada sob efeito residual da adubação com composto orgânico. Horticultura Brasileira, v.23, p.754-757, 2005. http://dx.doi.org/10.1590/S0102-

05362005000300013

TRANI, P.E.; TERRA, M.M.; TECCHIO, M.A. et al. Adubação orgânica de hortaliças e frutíferas.

Campinas: Instituto Agronômico de Campinas, 2013. 16p. Disponível em: http://www.iac.sp.gov.br/ imagem_informacoestecnologicas/83.pdf (Acessado em 09 de novembro de 2017).

ABCSEM - Associação Brasileira do Comércio de Sementes e Mudas. 2016. Disponível em: <http:// www.abcsem.com.br/upload/arquivos/

O_mercado_de_folhosas_Numeros_e_Tendencias_Steven.pdf $>$ (Ácessado em 10 de dezembro de 2017).

VIDIGAL, S.M.; RIBEIRO, A.C.; CASALI, V.W.D. et al. Resposta da alface (Lactuca sativa L.) ao efeito residual da adubação orgânica. Revista Ceres, v.42, p.239, p.80-88, 1995 .

Recebido para publicação em 13/12/2017 e aprovado em 6/9/2018. 